Journal of Engineering and Applied Sciences 14 (2): 567-574, 2019

ISSN: 1816-949X

(C) Medwell Journals, 2019

\title{
TGA, DSC, DTG Properties of Epoxy Polymer Nanocomposites by Adding Hexagonal Boron Nitride Nanoparticles
}

\author{
Ahmed A. Thamer, Hashim A. Yusr and Najwa J. Jubier \\ Department of Physics, College of Science, University of Wasit, Kut, Iraq
}

\begin{abstract}
In this study, the thermal analysis methods reported for the characterization of epoxy/h-BN nanocomposites were conducted using Thermogravimetric Analysis (TGA), Differential Thermal Analysis (DTA) and Differential Scanning Calorimetry (DSC). A thermosetting epoxy resin was mixed with a different weight percent of hexagonal Boron Nitride Nanoparticles (BNNPs) to prepare epoxy nanocomposites. Study of non-isothermal kinetics decomposition of epoxy and epoxy/BNNPs nanocomposites were carried out by utilizing Thermogravimetric Analysis (TGA). The samples were heated from room temperature to $600^{\circ} \mathrm{C}$ at a constant heating rate of $10^{\circ} \mathrm{C} / \mathrm{min}$ under oxidative atmosphere using air. TGA and DTG curves obtained from the decomposition were analyzed using the Coast-Redfern method. Kinetic parameters were determined for all specimens that show a good correlation with the linear correlation coefficient. Where Coats and Redfern procedure was the best to result in good estimates of the kinetic parameters.
\end{abstract}

Key words: Epoxy nanocomposites, boron nitride nanoparticles, thermal degradation and thermos-gravimetric analysis, DSC, DTA, epoxy/BNNPs

\section{INTRODUCTION}

Nanocomposites, a high-performance material in which at least one of the phases shows dimensions in the nanometer range $\left(1 \mathrm{~nm}=10^{-9} \mathrm{~m}\right)$. Where exhibit unusual property combinations and unique design possibilities. Being environmentally friendly, applications of nanocomposites offer new technology and business opportunities for several sectors of the aerospace, automotive, electronics and biotechnology industries (Camargo et al., 2009). The most common materials used as a matrix in nanocomposites are polymers (e.g., epoxy, nylon, polyepoxide, polyetherimide), ceramics, (e.g., alumina, glass, porcelain, boron nitride) and metals, (e.g., iron, titanium, magnesium) (Hu et al., 2010). Nanoparticles are a microscopic particle with at least one dimension $<100 \mathrm{~nm}$ (Naito et al., 2018). Hexagonal Boron Nitride (h-BN) is also known as 'white graphite' has a similar (hexagonal) crystal structure as of graphite. This crystal structure high thermal conductivity and chemical stability and provides excellent lubricating properties (Xue et al., 2014).

A very important process is thermal degradation which helps to know the polymer structure on the thermal stability, the optimum temperature of use, kinetic parameters and thermodynamic properties (Al-Bayaty and Farhan, 2015). In this study, influences of different weight fraction of boron nitride nanoparticles on the decomposition process of an epoxy polymer was investigated by Thermogravemetric Analysis (TGA), Derivative Thermo-Gravimetric (DTG) and Differential Scanning Calorimetry (DSC). The decomposition kinetic parameters of the mixtures were also determined according to the Coats-Redfern method. Several reports have been carried out about the investigated such properties as by Junwei et al. showed that the thermal conductivity of BN/EP composites exhibits a very high thermal conductivity and relatively good mechanical properties. The thermal conductivity of the composites increases with the increasing content of microparticle $\mathrm{BN}$ and also by TGA analysis showed that the thermal decomposition temperature increases with the increases concentration of $\mathrm{BN}$ ( $\mathrm{Gu}$ et al., 2012). Xiao et al. (2008) studied improving thermal properties Polyarylene Ether Nitrile (PEN) by the incorporation of Boron Nitride Nanosheet (BNNS), the results show a good thermal stability of BNNS/PEN nanocomposites, the glass transition temperatures and initial decomposition temperatures of them are higher than 200 and 4908 (Xiao et al., 2008).

Kinetics theory: The application of dynamic TGA, DSC and DTGA methods holds great promise as a tool for unraveling the mechanisms of physical and chemical processes that occur during solid's degradation. In this study, method Cost-Redfern has been used to analyze the

Corresponding Author: Ahmed A. Thamer, Department of Physics, College of Science, University of Wasit, Kut, Iraq 
non-isothermal kinetics. The pyrolysis process may be represented by the following reaction scheme (Al-Ayed).

$$
\mathrm{A}_{\text {(solid) }} \rightarrow \mathrm{B}_{\text {(solid) }}+\mathrm{C}_{\text {(volatile) }}
$$

Usually, the change in the extent of reaction $(\alpha)$ is used to study the solid state reactions kinetics:

$$
\alpha=\frac{m_{0}-m_{t}}{m_{0}-m_{\infty}}
$$

where, $\mathrm{m}_{0}, \mathrm{~m}_{\mathrm{t}}$ and $\mathrm{m}_{\infty}$ are initial sample mass, sample mass at time $\mathrm{t}$ and sample mass at the end of reaction, respectively (Ebrahimi-Kahrizsangi and Abbasi, 2008).

In the non-isothermal TGA experiments, the mass of the sample is measured as a function of temperature while the reaction proceeds for a constant heating rates, $\beta$ $\left({ }^{\circ} \mathrm{C} / \mathrm{min}\right.$ ) (Uzun and Yaman, 2015).

The rate of conversion $\mathrm{dx} / \mathrm{dt}$ for TGA experiment at constant heating rate of temperature change, $\beta=\mathrm{dT} / \mathrm{dt}$ may be expressed by Eq. 2 :

$$
\frac{\mathrm{dx}}{\mathrm{dt}}=\beta \frac{\mathrm{dx}}{\mathrm{dT}}=\mathrm{K}(\mathrm{T}) \mathrm{f}(\mathrm{x})
$$

Where:

$\mathrm{x}=$ The degree of advance

$\mathrm{f}(\mathrm{x})$ and $\mathrm{K}(\mathrm{T})=$ Function of conversion and Temperature, respectively

$\mathrm{K}(\mathrm{T})$, the temperature dependence of the rate of weight loss is often modeled successfully by Arrhenius equation (Eq. 3) (Aboulkas and El Harfi, 2008):

$$
\mathrm{K}(\mathrm{T})=\mathrm{A}_{0} \exp \left(\frac{-\mathrm{E}_{\mathrm{a}}}{\mathrm{RT}}\right)
$$

Where:

$\mathrm{E}_{\mathrm{a}}=$ The apparent activation Energy

$\mathrm{A}_{0}=$ The pre-exponential factor

$\mathrm{R}=$ The gas constant

Coats-Redfern is the most commonly used to find activation energy as follows:

$$
\operatorname{In}\left[\frac{-\operatorname{In}(1-\alpha)}{T^{2}}\right]=\operatorname{In}\left[\frac{\mathrm{A}_{0} \mathrm{R}}{\beta \mathrm{E}}\left(1-\frac{2 \mathrm{RT}}{\mathrm{E}}\right)\right]-\frac{\mathrm{E}}{\mathrm{RT}}
$$

Plotting $\ln \left[\left\{\ln (1-\alpha) / \mathrm{T}^{2}\right]\right.$ against $1000 / \mathrm{T}$, to determine the activation energy from the slope of the linear expression, the value of frequency factor $\left(\mathrm{A}_{0}\right)$ can be determined from the intercept on the $\mathrm{y}$-axis and by substituting values of activation energy in Eq. 5 (Kim and Oh, 2005; Maitra et al., 2007):

$$
\text { Intercept }=\operatorname{In}\left(\frac{A_{0} R}{\beta E}\right)\left\{1-\frac{2 R T}{E_{a}}\right\}
$$

\section{MATERIALS AND METHODS}

Experimental: A commercial epoxy (EUXIT 50) is primarily low viscosity (highly fluid) special mixture with high capillary action. Mix ratio (by weight) of the epoxy resin to the hardener was 3:1, viscosity equal 1 (poise) at 20 . The properties of the epoxy resin are specific density $\left(\mathrm{g} / \mathrm{cm}^{3}\right)$ at 20 is 1.05 produced by Egyptian Swiss chemical industries company was used in this present investigation.

Samples of the epoxy and epoxy nanocomposites at a different weight percentage of hexagonal boron nitride nanoparticles $(0.5,0.7,1.2$ and $5 \%)$ are prepared by hand lay-up technique and mixing process. All content mixed thoroughly before casting, then the samples left at room temperature for one day and then for post curing, the sample sheets were left for $1 \mathrm{~h}$ in an oven at temperature 50 .

The hexagonal boron nitride Nanoparticles (NPs) utilized in the present study have been procured from (US Research Nanomaterials inc. USA) (99.8+\% purity as per suppliers data), Atomic Force Microscopy (AFM) was used (CSPM Scanning Probe Microscope) to measure the average particles size, surface roughness and Root Mean Square (RMS) of BN nanoparticles as shown in Table 1, Fig. 1 shows image (3D-AFM) of nanoparticles boron nitride and the particles size distribution.

The thermogravemetric measurement was carried out by a Linseis STA PT1000 TG-DSC (STA Simultaneous Thermal Analysis) analyzer in non-isothermal condition. This experiment was carried out at Ibn AL-Haitham Company (Central Service Laboratory). The sample weights were $(21 \mathrm{mg})$. Decomposition profiles were obtained with a constant heating rate $10 / \mathrm{min}$ in the oxidative atmosphere using air.

Table 1: Average diameter, surface roughness and root mean square values of nanoparticles boron nitride

\begin{tabular}{lcccc}
\hline Material & $\begin{array}{l}\text { Average } \\
\text { diameter }(\mathrm{nm})\end{array}$ & $\begin{array}{l}\text { Surface } \\
\text { roughness }(\mathrm{nm})\end{array}$ & $\begin{array}{c}\text { RMS } \\
(\mathrm{nm})\end{array}$ & $\begin{array}{c}\text { Peak-to-peak } \\
(\mathrm{nm})\end{array}$ \\
\hline Boron nitride & 52.91 & 2.83 & 3.27 & 11.3 \\
\hline
\end{tabular}



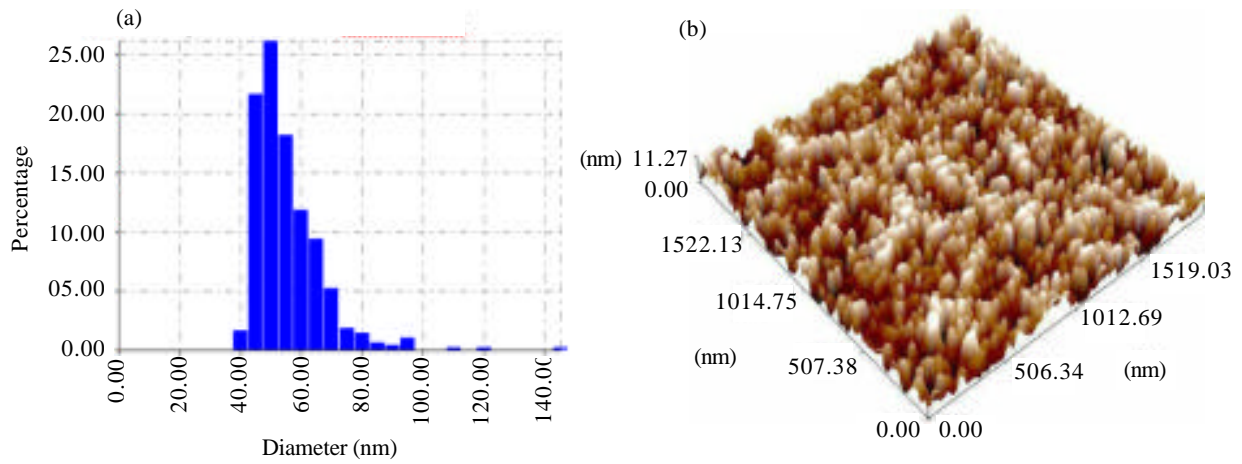

Fig. 1: AFM of nanoparticles boron nitride; a) Granularity distribution of nanoparticles; b) 3D image AFM

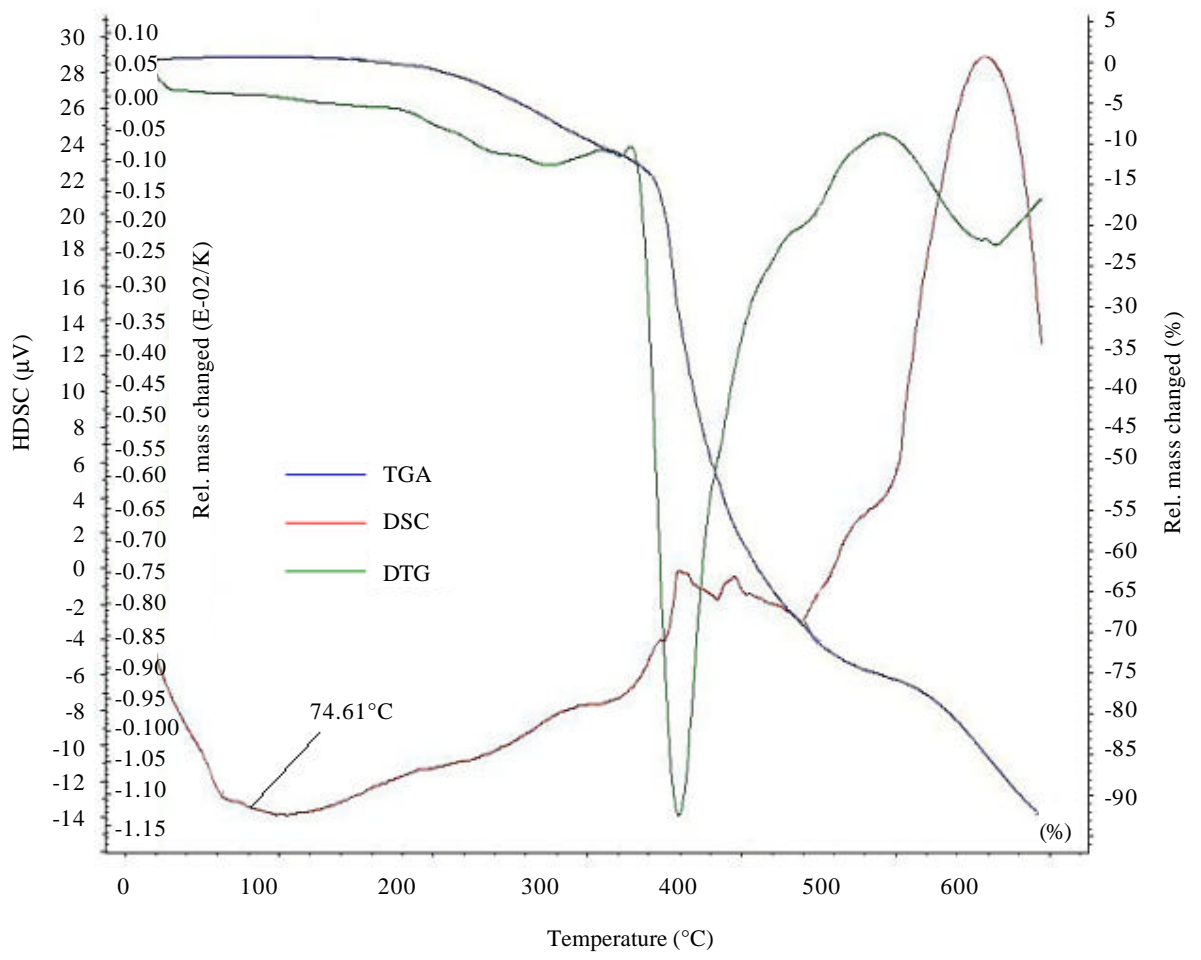

Fig. 2: TGA, DSC, DTG curves of pure epoxy resin at hating rate $10^{\circ} \mathrm{C} / \mathrm{min}$

\section{RESULTS AND DISCUSSION}

Thermogravemetric Analysis(TGA): Thermogravemetric Analysis (TGA) has been used as a means of determining pyrolysis characteristics and also to determine kinetic parameters (Uzun and Yaman, 2015) TGA and DTG for pure epoxy and epoxy/BNNPs nanocomposites are shown in Fig 2-7 at heating rate $10 /$ min under oxidative atmosphere using air. Mass loss of degraded nanocomposites as a function of temperature was determined by a TGA technique and was an irreversible process. Table 2 shows the loss mass due to decomposition of the thermosetting epoxy resin and with various contents of BNNPs. From Fig. 2-6, it was showed that the pure epoxy have a two stage mass loss while epoxy/BNNPs nanocomposites have a two stage in the $0.5,0.7,1 \mathrm{wt} . \%$ and 3 stages in $2,5 \mathrm{wt} . \%$. This means that when increasing the ratio of BNNPs in the epoxy resin will lead to increase the number stages of in the decomposition it was also noticed that the rate of mass loss during degradation at $592^{\circ} \mathrm{C}$ of nanocomposites is lower than pure epoxy, since, its thermal stability was increase and the degradation process shift to a higher temperature.

Differential Scanning Calorimetry (DSC): Differential Scanning Calorimetry (DSC) analysis was carried out to study the cure properties of the epoxy resin and 


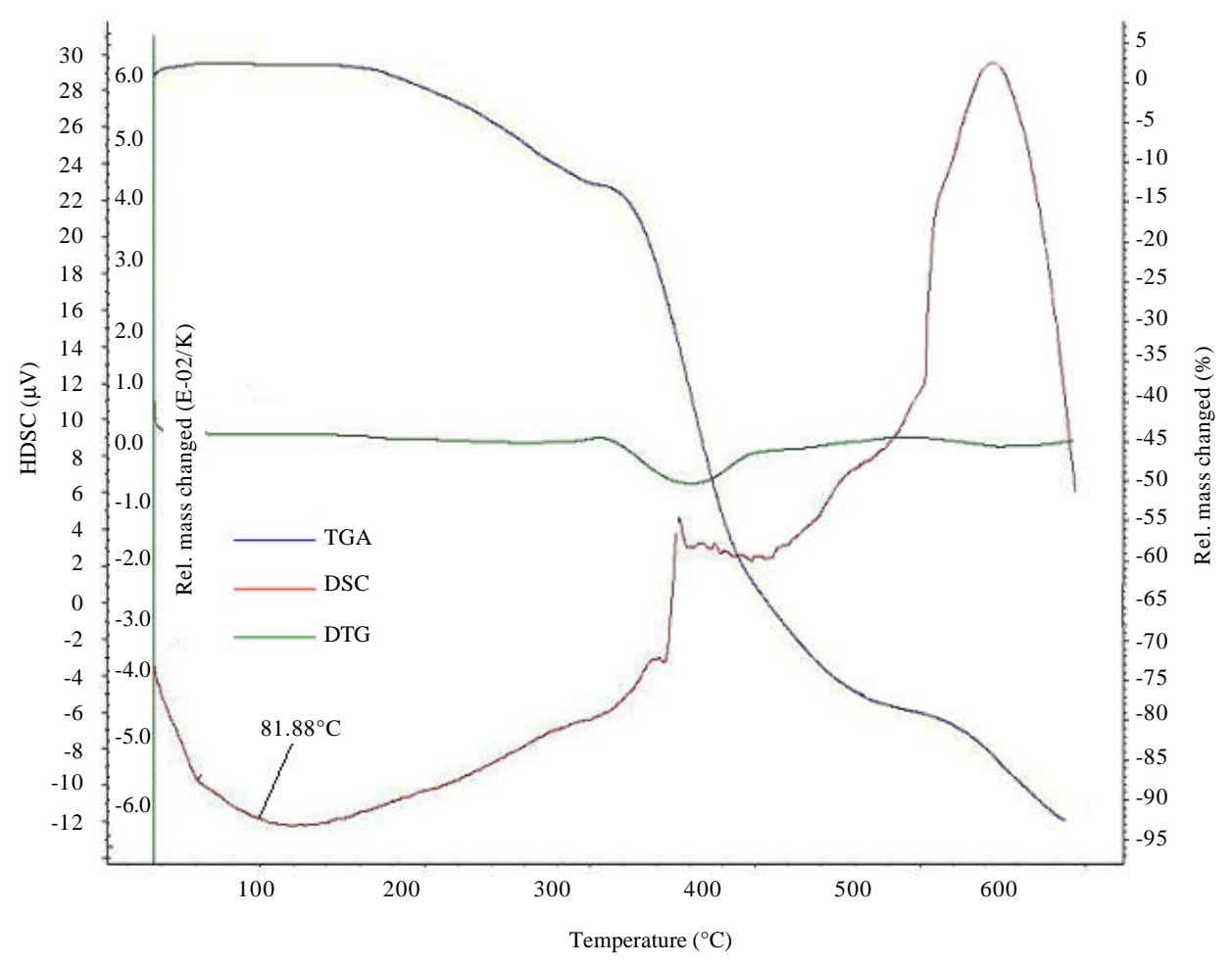

Fig. 3: TGA, DSC, DTG curves of epoxy/BNNPs $0.5 \mathrm{wt} . \%$ at hating rate $10^{\circ} \mathrm{C} / \mathrm{min}$

Table 2: The mass loss of the epoxy resin with various contents of BNNPs

\begin{tabular}{lllll}
\hline Samples & First stage mass loss $(\%)$ & Second stage mass loss (\%) & Third stage mass loss (\%) & Total mass loss $(\%)$ at $592^{\circ} \mathrm{C}$ \\
\hline Epoxy pure & $448.56^{\circ} \mathrm{C},-71.26$ & $594.5^{\circ} \mathrm{C},-21.2$ & - & -92.46 \\
Epoxy+0.5 BN & $463.9^{\circ} \mathrm{C},-79.02$ & $593.57^{\circ} \mathrm{C},-16.4$ & - & -95.42 \\
Epoxy+0.7 BN & $428.51^{\circ} \mathrm{C},-73.84$ & $594.10^{\circ} \mathrm{C},-26.42$ & - & -100.26 \\
Epoxy+1 BN & $454.01^{\circ} \mathrm{C},-70.18$ & $594.16^{\circ} \mathrm{C},-22.73$ & - & -92.91 \\
Epoxy+2 BN & $314.81^{\circ} \mathrm{C},-20.89$ & $443.32^{\circ} \mathrm{C},-53.83$ & $591.35^{\circ} \mathrm{C},-26.29$ & -101.07 \\
Epoxy+5 BN & $325.57^{\circ} \mathrm{C},-14.26$ & $442.62^{\circ} \mathrm{C},-49.65$ & $594.09^{\circ} \mathrm{C}, 24.3$ & -88.21 \\
\hline
\end{tabular}

Table 3: The glass transition temperature

\begin{tabular}{lr} 
BNNPs (wt.\%) & TGA $\left({ }^{\circ} \mathrm{C}\right)$ \\
\hline 0.0 & 74.61 \\
0.5 & 81.88 \\
0.7 & 102.73 \\
1.0 & 123.72 \\
2.0 & 123.82 \\
5.0 & 110.01 \\
\hline
\end{tabular}

epoxy/BNNPs nanocomposites as shown in Fig. 2-6. Dynamic scans were made from room temperature to $600^{\circ} \mathrm{C}$ at a constant heating rate $10^{\circ} \mathrm{C} / \mathrm{min}$ under oxidative atmosphere using air. The value of glass transition temperature was determined from Fig. 2-6. It was noticed that the glass transition temperature increased with the increase in the weight fraction of boron nitride nanoparticles as shown in Table 3 . Where the addition of nanoparticles in epoxy matrix lead to reduce the mobility of the epoxy chains due to formation high immobility monolayer around each nanoparticle while the matrix chains (epoxy chains not bonded to nanoparticles) bonded to that monolayer constrained the non-contact matrix chains, so, the network of nanoparticles reduce the overall mobility of the nanocomposites system. Due to reducing free volume space occupied by the spaces at the end of chains.

Kinetics of thermal decomposition: The Coast-Redfern integral kinetic method was applied to calculate the kinetic parameters. This method can determine the decomposition activation energy by specifying a heating rate. In this study, the TGA curves at a heating rate of $10^{\circ} \mathrm{C} / \mathrm{min}$ were used to calculate the degradation kinetics for all samples using Eq. 4. The results are given in Table 4.

The activation energy increased gradually when boron nitride nanoparticles were added to epoxy from $59.323 \mathrm{~kJ} / \mathrm{mol}$ for the pure epoxy to $105.311 \mathrm{~kJ} / \mathrm{mol}$ at ratio $5 \mathrm{wt} \%$ of BNNPs. The increasing in the value of activation energy is due to the increase in the decomposition temperature of all examined samples in turn 


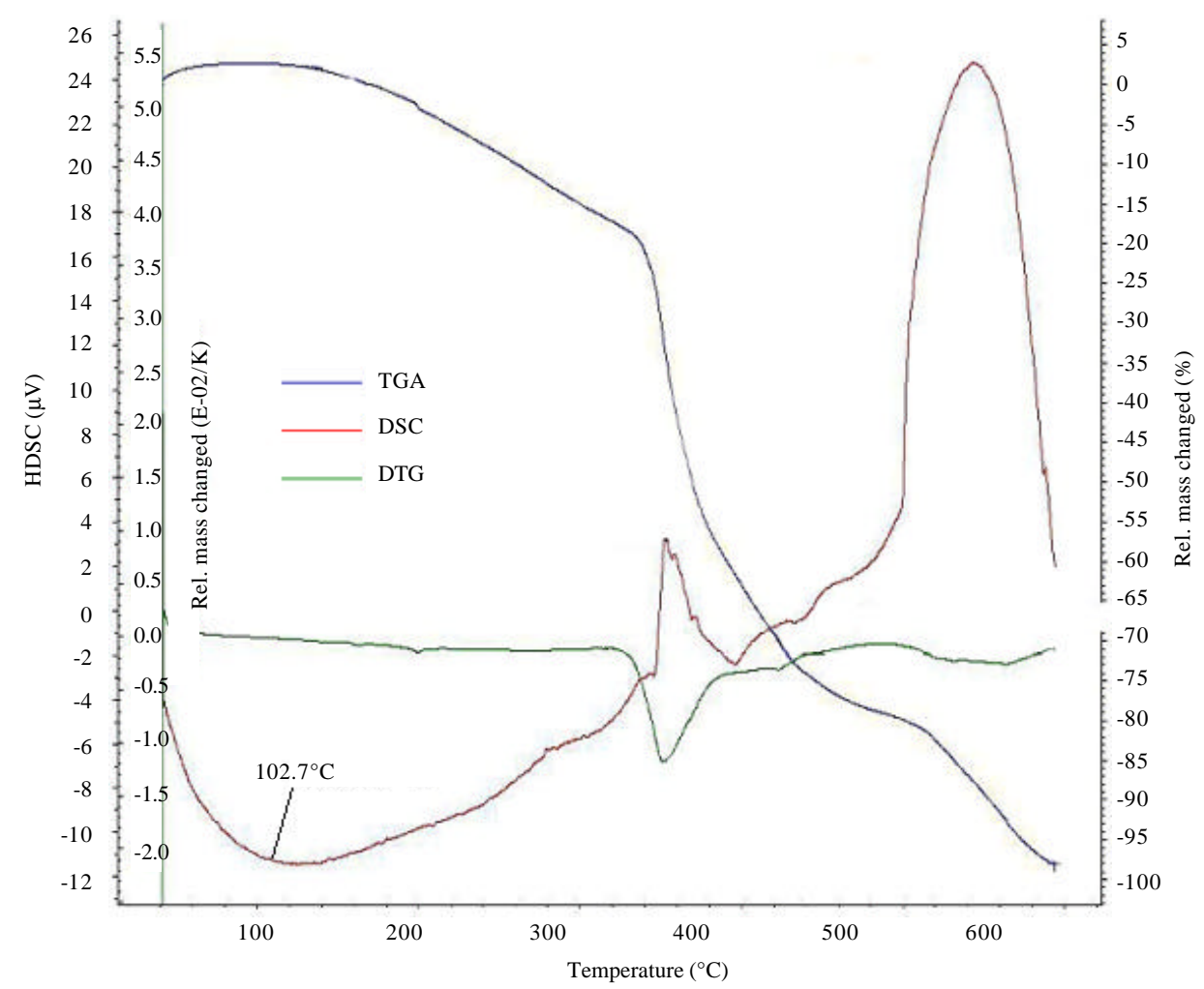

Fig. 4: TGA, DSC, DTG curves of epoxy/BNNPs $0.7 \mathrm{wt} . \%$ at hating rate $10^{\circ} \mathrm{C} / \mathrm{min}$

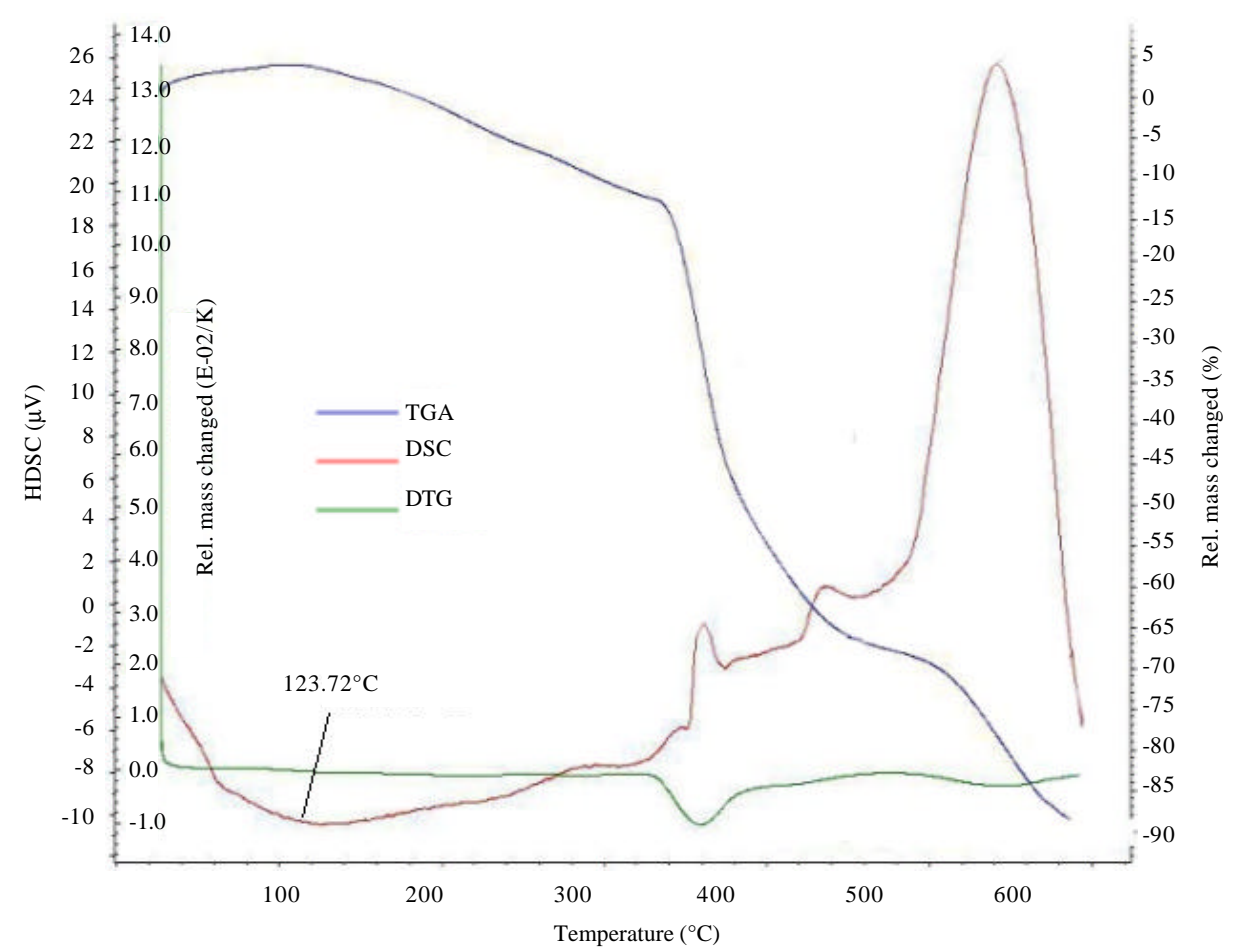

Fig. 5: TGA, DSC, DTG curves of epoxy/BNNPs $1 \mathrm{wt} \%$ at hating rate $10^{\circ} \mathrm{C} / \mathrm{min}$

thermal stability will increases as shown in Table 4 . of different weight fraction and at constant heating Figure 8 shows Coast-Redfern plot of epoxy/BNNPs rates. The results obtained are shown in the Table 4 . 


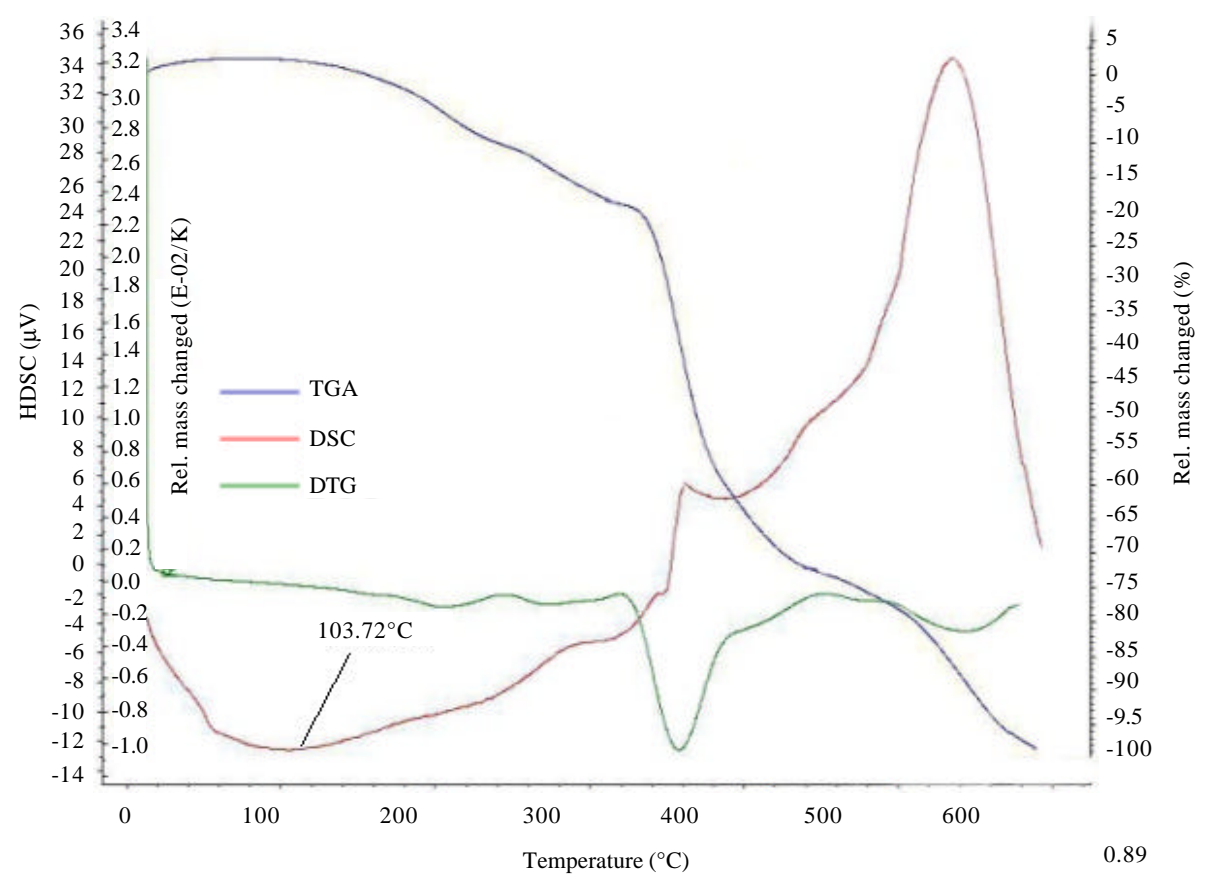

Fig. 6: TGA, DSC, DTG curves of epoxy/BNNPs $2 \mathrm{wt} . \%$ at hating rate $10^{\circ} \mathrm{C} / \mathrm{min}$

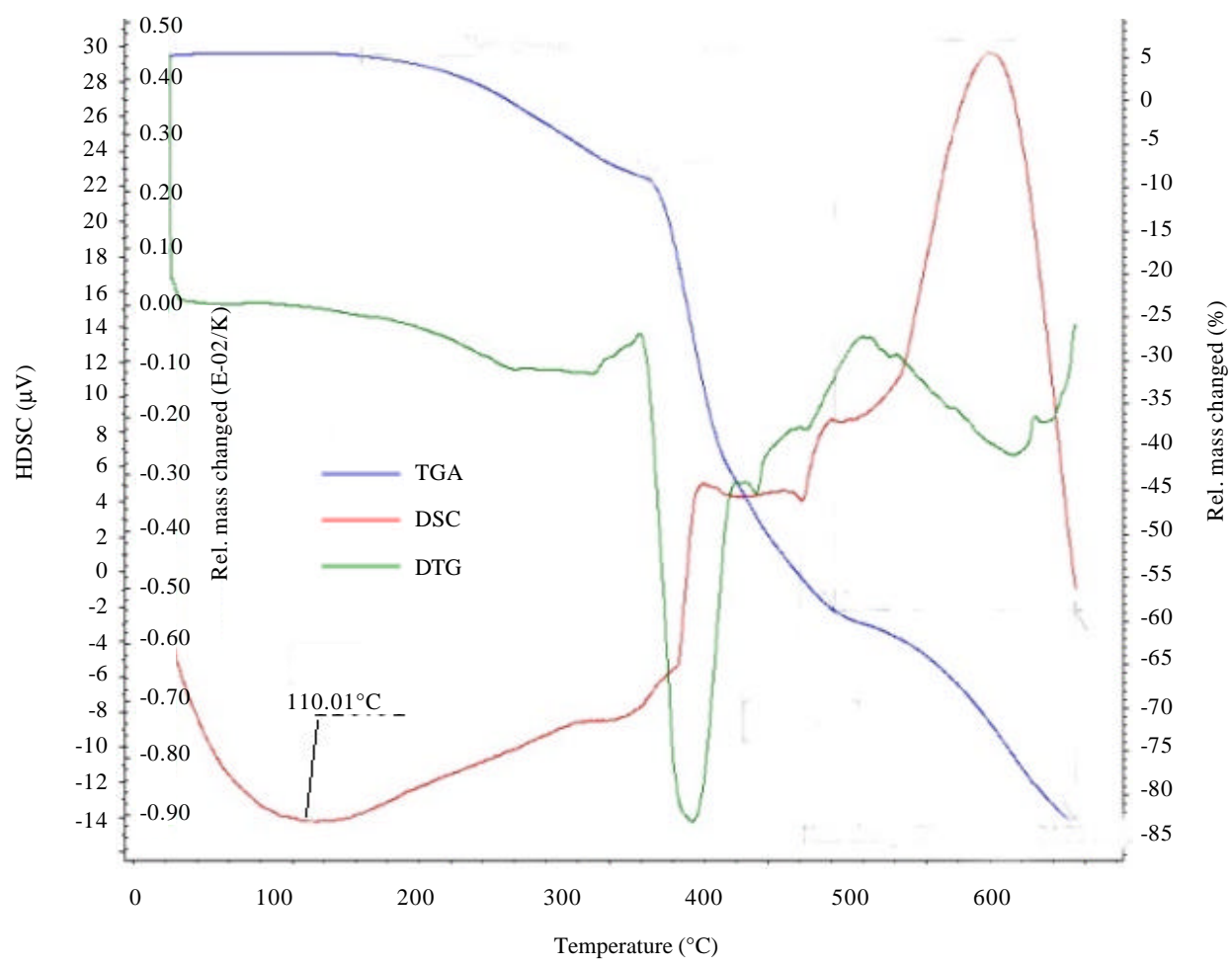

Fig. 7: TGA, DSC, DTG curves of epoxy/BNNPs $5 \mathrm{wt} . \%$ at hating rate $10^{\circ} \mathrm{C} / \mathrm{min}$

It was noticed there is a linear dependence between $\ln \mathrm{A}_{0}$ and $\mathrm{E}_{\mathrm{a}}$ (Fig. 9) which gives a proof that the mechanistic kinetic equations employed adequately reflect the specific kinetic parameters, it means that the most probable kinetic equations found describe correctly the mechanism of thermal destruction of the samples (Al-Bayaty and Farhan, 2015; Turmanova et al., 2008). 
Table 4: Results of the non-isothermal kinetic analysis for epoxy/NNPs nanoc omposites using coast-redfern method

\begin{tabular}{lcrcr}
\hline \multicolumn{5}{c}{ nanocomposites using coast-redfern method } \\
$\begin{array}{lcccc}\text { BNNPs } \\
\text { (wt.\%) }\end{array}$ & $\begin{array}{c}\text { Peak } \\
\text { temperature }(\mathrm{K})\end{array}$ & $\begin{array}{c}\text { Activation energy } \\
\mathrm{E}_{\mathrm{a}}(\mathrm{kJ} / \mathrm{mol})\end{array}$ & $\begin{array}{c}\text { Reaction rate }\left(\mathrm{S}^{-1}\right) \\
\text { Constant }\left(\mathrm{A}_{0}\right)\end{array}$ & $\mathrm{R}^{2}$ \\
\hline 0.0 & 632.391 & 59.323 & $4.62 \mathrm{E}+05$ & 0.999 \\
0.5 & 629.576 & 60.695 & $7.27 \mathrm{E}+05$ & 0.994 \\
0.7 & 619.154 & 62.557 & $1.10 \mathrm{E}+06$ & 0.999 \\
1.0 & 632.255 & 69.361 & $2.81 \mathrm{E}+06$ & 0.999 \\
2.0 & 630.707 & 82.214 & $2.70 \mathrm{E}+07$ & 0.990 \\
5.0 & 624.100 & 105.311 & $5.13 \mathrm{E}+09$ & 0.998 \\
\hline
\end{tabular}

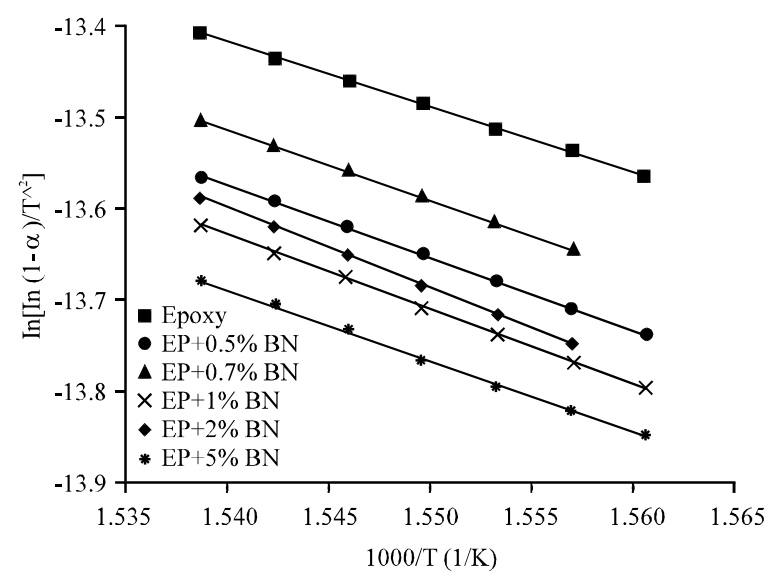

Fig. 8: Coast-Redfern plot for thermal degradation of $\mathrm{Ep} / \mathrm{BNNPs}$ nanocomposites at constant heating rate $10^{\circ} \mathrm{C} / \mathrm{min}$

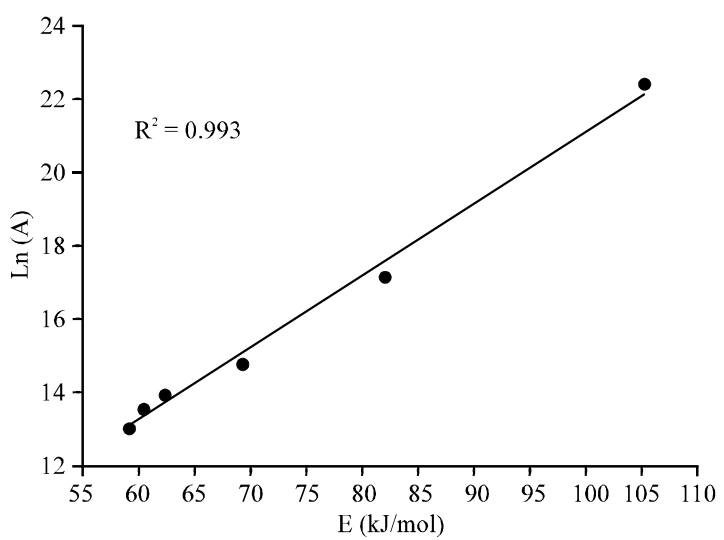

Fig. 9: Plot of activation energy versus $\ln \mathrm{A}_{0}$ for the thermal decomposition of Ep/BNNPs

Thermodynamic parameters: Thermodynamic functions were calculated according to the following relationships (Low et al., 1973; Ramukutty and Ramachandran, 2014):

$$
\begin{aligned}
& \Delta \mathrm{H}=\mathrm{E}-\mathrm{RT}_{\text {peak }} \\
& \Delta S=R\left[\operatorname{In}\left(\mathrm{h} \mathrm{A}_{0} / \mathrm{KbT}_{\text {peak }}\right)-1\right]
\end{aligned}
$$

Table 5: Thermodynamics parameter for pure epoxy and epoxy/BNNPs nanocomposites

\begin{tabular}{llllll}
\hline BNNPs & $\begin{array}{l}\text { Activation } \\
\text { energy }(\mathrm{E})\end{array}$ & $\begin{array}{l}\text { Reaction rate } \\
\text { constant, } \\
(\mathrm{wt} . \%)\end{array}$ & $\begin{array}{l}\Delta \mathrm{H} \\
(\mathrm{kJ} / \mathrm{mol})\end{array}$ & $\begin{array}{l}-\Delta \mathrm{S} \\
\mathrm{A}_{0}\left(\mathrm{~S}^{-1}\right)\end{array}$ & $\begin{array}{l}\Delta \mathrm{G} \\
(\mathrm{kJ} / \mathrm{mol})\end{array}$ \\
\hline 0.0 & 59.323 & $4.62 \mathrm{E}+05$ & 54.065 & 151.044 & 95.573 \\
0.5 & 60.695 & $7.27 \mathrm{E}+05$ & 55.460 & 147.239 & 92.753 \\
0.7 & 62.557 & $1.10 \mathrm{E}+06$ & 57.409 & 143.681 & 89.018 \\
1.0 & 69.361 & $2.81 \mathrm{E}+06$ & 64.105 & 136.029 & 86.069 \\
2.0 & 82.214 & $2.70 \mathrm{E}+07$ & 76.970 & 117.191 & 73.990 \\
5.0 & 105.311 & $5.13 \mathrm{E}+09$ & 100.750 & 73.432 & 146.038 \\
\hline
\end{tabular}

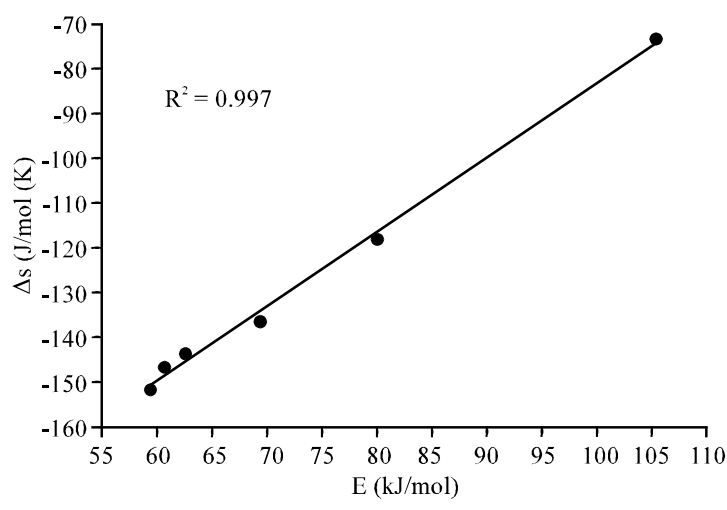

Fig. 10: Plot activation energy $\mathrm{kJ} / \mathrm{mol}$ versus $\Delta \mathrm{S}(\mathrm{J} / \mathrm{mol} \mathrm{K})$

$$
\Delta \mathrm{G}=\Delta \mathrm{H}-\mathrm{T}_{\text {peak }} \Delta \mathrm{S}
$$

The thermodynamic parameters of: entropy of activation $\Delta \mathrm{S}$ enthalpy of activation $\Delta \mathrm{H}$ and free energy of decomposition $\Delta \mathrm{G}$ and $\mathrm{T}_{\text {peak }}$ is the maximum peak temperature, $\mathrm{h}$ plank constant and $\mathrm{kb}$ is Boltzmann constant, Table 5 shows the thermodynamics parameter of pure epoxy and epoxy/BNNPs nanocomposites. It is observed that the entropy of activation increases with the increase of activation energy the positive value of $\Delta \mathrm{G}$ shows that the reaction involved in the decomposition of BNNPs nanocomposites is not spontaneous. However, there is a linear dependence between the entropy $\Delta \mathrm{S}$ and the activation energy $E_{a}$ as shown in Fig. 10.

\section{CONCLUSION}

TGA, DTG and DSC analysis of nanocomposites shows enhancement in the thermal stability of nanocomposites, the TG will increased when increased the weight fraction of boron nitride nanoparticles and the activation energy, activation entropy show the linear relationship between them that's mean the composites BNNPs has a high thermal stability. 


\section{REFERENCES}

Aboulkas, A. and K. El Harfi, 2008. Study of the kinetics and mechanisms of thermal decomposition of Moroccan Tarfaya Oil Shale and its Kerogen. Oil Shale, 25: 426-443.

Al-Bayaty, S.A. and A.J. Farhan, 2015. Thermal decomposition kinetics unsaturated polyester and unsaturated polyester reinforcement by Toner Carbon Nano Powder (TCNP) composites. Intl. J. Appl. Innovation Eng. Manage., 4: 139-146.

Camargo, P.H.C., K.G. Satyanarayana and F. Wypych, 2009. Nanocomposites: synthesis, structure, properties and new application opportunities. Mater. Res., 12: 1-39.

Ebrahimi-Kahrizsangi, R. and M.H. Abbasi, 2008. Evaluation of reliability of Coats-Redfern method for kinetic analysis of non-isothermal TGA. Trans. Nonferrous Met. Soc. China, 18: 217-221.

Gu, J., Q. Zhang, J. Dang and C. Xie, 2012. Thermal conductivity epoxy resin composites filled with Boron Nitride. Polym. Adv. Technol., 23: 1025-1028.

Hu, H., L. Onyebueke and A. Abatan, 2010. Characterizing and modeling mechanical properties of nanocomposites-review and evaluation. J. Miner. Mater. Charact. Eng., 9: 275-319.

Kim, H.T. and S.C. Oh, 2005. Kinetics of thermal degradation of waste polypropylene and highdensity polyethylene. J. Ind. Eng. Chem., 11: 648-656.

Low, P.S., J.L. Bada and G.N. Somero, 1973. Temperature adaptation of enzymes: Roles of the free energy, the enthalpy and the entropy of activation. Proc. Nat. Acad. Sci., 70: 430-432.
Maitra, S., S. Mukherjee, N. Saha and J. Pramanik, 2007. Non-isothermal decomposition kinetics of magnesite. Ceram., 53: 284-287.

Naito, M., T. Yokoyama, K. Hosokawa and K. Nogi, 2018. Nanoparticle Technology Handbook. 3rd Edn., Elsevier, New York, USA., ISBN:9780444641113, Pages: 904.

Ramukutty, S. and E. Ramachandran, 2014. Reaction rate models for the thermal decomposition of ibuprofen crystals. J. Cryst. Proc. Technol., 4: 71-78.

Turmanova, S.C., S.D. Genieva, A.S. Dimitrova and L.T. Vlaev, 2008. Non-isothermal degradation kinetics of filled with rise husk ash polypropene composites. Express Polym. Lett., 2: 133-146.

Uzun, B.B. and E. Yaman, 2015. Thermogravimetric pyrolysis of walnut shell an assessment of kinetic modeling. Proceedings of the International Conference on Industrial Waste and Waste Water Treatment Valorization, May 21-23, 2015, IWWATV, Athens, Greece, pp: 1-18.

Xiao, Q., W. Han, R. Yang, Y. You and R. Wei et al., 2018. Mechanical, dielectric and thermal properties of polyarylene ether nitrile and boron nitride nanosheets composites. Polym. Compos., 39: E1598-E1605.

Xue, Y., X. Jin, Y. Fan, R. Tian and X. Xu et al., 2014. Large-scale synthesis of hexagonal boron nitride nanosheets and their improvement in thermal properties of epoxy composites. Polym. Compos., 35 : 1707-1715. 